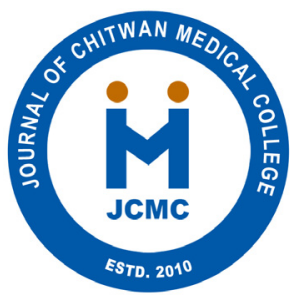

\title{
PROSPECTIVE STUDY ON THE EFFICACY OF TAMSULOSIN IN MEDICAL MANAGEMENT OF DISTAL URETERIC STONES
}

\author{
S Basnet ${ }^{1}$, P M Shrestha ${ }^{2}$ and R Shakya*1 \\ ${ }^{1}$ Department of Pharmacy, Kathmandu University, Dhulikhel, Kavre, Nepal. \\ ${ }^{2}$ Department of Urology, NAMS, Bir Hospital, Kathmandu, Nepal. \\ *Correspondence to : Dr Rajani Shakya, Department of Pharmacy, Kathmandu University, Dhulikhel, Kavre, Nepal.Email: rajani@ku.edu.np
}

\begin{abstract}
A non-interventional prospective study was done in patients having single distal ureteral stone less than $10 \mathrm{~mm}$ to find the effectiveness of two weeks course of Tamsulosin $0.4 \mathrm{mg}$ in the stone expulsion; the reduction of occurrence of ureteral, reduction in rate of use of analgesic agents and the side effects of the drug. Thirty patients, having stone size $\leq 10.0 \mathrm{~mm}$ were revealed initially by patient's symptoms and then confirmed by ultrasonography (USG) followed by Intravenous Urography (IVU) radiographic images. The expulsion rate of distal ureteral stones having size $\leq 10.0 \mathrm{~mm}$ was found to be $76.66 \%$ ( 27 out of 30), with only $26.66 \%$ of analgesic consumption, with decrease in colic episodes by $36.66 \%$ and lesser evidence of side effects. The expulsion rate for stone size less than $7.0 \mathrm{~mm}$ is $36.72 \%$ with mean of expulsion days as $5.90 \pm 1.92$. The expulsion rate for stone size more than $7.0 \mathrm{~mm}$ is $63.33 \%$ with mean of expulsion days as $9.33 \pm 27$. The correlation between the size and expulsion days is statistically significant with $p$-value of $0.00057(p=0.01)$. The observed side effects were orthostatic hypotension $(26.7 \%)$, headache $(13.3 \%)$, dizziness $(6.7 \%)$, sore throat $(6.7 \%)$ followed by fatigue $(3.3$ $\%$ ), abnormal ejaculation (3.3\%) and no any side effect was observed in $56.7 \%$ patients. Considering the economic value and its effectiveness, the MET using Tamsulosin $0.4 \mathrm{mg}$ can be the possible intervention for the medical treatment of distal ureteral stones having less than $10 \mathrm{~mm}$ stone size.
\end{abstract}

Key Words: Tamsulosin, Medical expulsive therapy, distal ureteral stones \& stone size

\section{INTRODUCTION}

As a major health problem, urolithiasis constitutes the third most common disease of the urinary tract, affecting $2-3 \%$ of the population, with a high recurrence rate of almost $50 \%{ }^{1}$ Ureteric stones occupy an important place in daily urological practice, ${ }^{2}$ and clinicians are frequently asked to choose adequate treatment. ${ }^{3}$ Recently, use of the watchful waiting approach has been extended by using pharmacological therapy, which can reduce symptoms and facilitate stone expulsion. ${ }^{4}$ Medical expulsive therapy (MET) has been recommended to promote stone passage and reduce the need for ESWL or minimally invasive surgery. ${ }^{5}$ The majority of individuals with urolithiasis have small stones, located in the distal ureter, that are able to pass spontaneously. Both stone expulsion and time to expulsion of ureteric stones depend heavily on stone size and location. ${ }^{6}$ Several drugs-such as alpha-1 blockers, calcium channel blockers, prostaglandins synthesis inhibitors, glyceryl trinitrate, and steroids have been used to facilitate spontaneous passage of ureteric stones. ${ }^{7}$ Of these agents, alpha-1 blocker, Tamsulosin has been found effective in the medical expulsive management of such stones by increasing the likelihood of spontaneous stone passage in a relatively shorter time period while decreasing the need for hospitalization. prevents the loss of more working days, hospitalization costs, need of several urgent urological visits, the need of pain management and the need of surgery/ESWL. ${ }^{8}$ Alpha-1 blockers have been used to inhibit basal ureteric wall tone, decrease ureteric peristaltic frequency, and reduce ureteric spasm.

Alpha-1 receptors, particularly subtype alpha-1D, are present in high density in the lower ureteric segment and may play an important role in lower-ureteric physiology through an effect on detrusor and ureteric smooth-muscle contraction. ${ }^{5}$ Tamsulosin for the treatment of distal ureteric stones arose from the concept that they can induce selective relaxation of the ureteric smooth muscle, which will inhibit ureteric spasms and result in dilatation of the ureteric lumen. It inhibits the contraction of ureteric muscle responsible for ureteric spasms while allowing antegrade stone propagation. ${ }^{6}$ This facilitates the passage of stone from the urinary tract. Tamsulosin has a greater affinity for alpha1-adrenoceptors in the prostate and distal ureter than in the vasculature. In in vitro studies, Tamsulosin showed a 10fold selectivity for human prostatic and ureteric tissue over mesenteric arteries, as measured by the ratio of molar affinities, 
and an approximately 12-fold greater affinity binding sites in human prostatic and ureteric tissue than in aortic tissue. Modified-release Tamsulosin has a low potential to cause vasodilation and associated cardiovascular adverse effects. ${ }^{9}$

Urolithiasis is one of the commonest urological disorders in Nepal. ${ }^{10}$ Considering the economic condition of the country and various complications of non conservative treatments (ESWL/ ureteroscopic lithotripsy/surgery), the MET for ureteric stones can be the preferable, promising and economic choice of treatment. ${ }^{1}$ Tamsulosin represents a noninvasive and cost-effective alternative to interventional approaches with fewer side effects like abnormal ejaculation, hypotension and asthenia. ${ }^{[11]}$ In comparative study of three alpha-1 adrenergic by Erdal Yalmaz et al, 2005, the calculi passed through the ureter spontaneously in 15 of 28 patients in control group $(53.57 \%)$, 23 of 29 patients in group treated with Tamsulosin $(79.31 \%), 22$ of 28 patients in group treated with terazosin $(78.57 \%)$, and 22 of 29 patients in group treated with doxazocin $(75.86 \%)$. The average time of expulsion was 6.31(1 to 11) in group treated with Tamsulosin. ${ }^{12}$

We believe that Tamsulosin will be beneficial to patients' quality of life. This study can be helpful for doctors and patients for understanding the advantages and effectiveness of MET with the use Tamsulosin $0.4 \mathrm{mg}$.Capsule.

\section{MATERIALS AND METHODS}

This study was non-interventional and prospective cross sectional conducted in Urological Department of Bir Hospital, Kathmandu, Nepal from March, 2011 to July, 2011. Total thirty Patients who were over 18 years having Radio-opaque urolithiasis with single Stone size less than or equal to $10.0 \mathrm{~mm}$ was taken for this study Patient with Pregnancy or breast-feeding,Treatment with alpha or beta-blocker, Contraindication to Tamsulosin, Complication needing surgery (signs of obstructive Hydronephrosis), Allergy to sulpha drugs, Concomitant treatment with alpha-lytic drugs/calcium channel antagonists/nitrates/verdenafil, Liver failure and renal failure, Single kidney patients, Bilateral ureteric obstruction were excluded from the study.

The patients having ureteric stones with a diameter less than or equal to $10 \mathrm{~mm}$ are included into the study programme. An explanation was given to the patients including the reason why he or she was prescribed Tamsulosin, the possible side effects and effectiveness of the drug and their written approval was taken. All the patients had medical examination, renal function test (serum creatinine) white blood cell count, and urinalysis including urine culture done in addition to abdominal USG followed by IVU. The stone sizes were measured specifically for this study in millimeters from IVU of each patient. The diagnostic tools used were: the patients' symptoms, findings from abdominal USG, IVU, urinalysis results and biochemistry results. Tamsulosin $400 \mathrm{mcg}$ capsule was prescribed orally once a day to patients for two weeks. Antibiotics were also used in these studies in case of positive culture test of urine sample to treat urinary tract infection. The routine follow-up examinations were performed, using the same diagnostic tools to evaluate the success of the treatments in every 7 days till two weeks of study period. Patients were instructed to discontinue the study medication after spontaneous stone expulsion and date of expulsion is to be recorded. For patients without stone in urinary tract on final USG report or KUB x-ray report but unnoticed stone expulsion, the date of last positive stone status is to be recorded. The structured questionnaires regarding the recurrence of colic pain, need of pain management, possible side effects of the drug and the improvements in symptoms after the MET were used in the direct interview with patient or caretaker during every follow up examinations were focused.

\section{Outcome Variables}

The primary outcome was the efficacy of MET which is determined by expulsion of distal ureteral stone during urination. Secondary outcomes included recurrence of colic pain, requirement of analgesic for pain during MET, improvement in the urinary tract symptoms, side effects of Tamsulosin and the cost effectiveness of MET for stone expulsion.

\section{Statistical Analysis}

Data collection and statistical analysis were done using SPSS 15.0. The different study variables were analysed using descriptive statistics. The different tests such as paired sample test, correlation tests and descriptivec statist were applied as appropriate to analyze the data.

\section{RESULTS AND DISCUSSION}

The diagnosis of distal ureteric stone was established in 30 patients, which was revealed initially by patient's symptoms and then confirmed by USG and IVU radiographic images.

\section{Patients' Distribution According to the Gender and age:}

Among thirty patients, affected by the ureteric stones majority were male. There were 18 (60\%) male patients and $12(40 \%)$. were female patients. The ratio of male: female was 1.5: 1 . The result indicates that prevalence of distal ureteric stone is more in male than in female. In other study done in NAMS, Bir Hospital, Kathmandu, the total number of male patient was 28 (56\%) while the number of female patient was 22 (44\%). There was male predominance, male:female ratio being 1:0.78. ${ }^{9}$ Diet and lifestyle may have a role. Increase in metabolic risk factors, which lead to stone formation have been linked with increasing body mass index and obesity. The combined prevalence of overweight and obesity is higher in men than in women. ${ }^{13}$

\section{Habit of Water Intake of the patients}

Among thirty patients involved in this study $70 \%$ were consuming less than two litres of water.

The National Institutes of Health recommend drinking up to 12 full glasses of water a day. A low intake of fluid increases the risk of forming stones by increasing the concentration of stoneforming salts. ${ }^{14}$

The prophylactic measures of ureteric stones formation is based on a high hydric ingestion (at least $4 \mathrm{~L}$ of water daily). ${ }^{15}$ Stone formers should drink enough fluid to maintain a urine output of 2 liters per day. A low urine volume is among the most common metabolic abnormality found in stone formers and this is a modifiable risk factor. ${ }^{16}$

\section{Dietary habits of patients}

Diet and fluid intake have been identified as important modifiable risk factors that have a marked effect on urinary constituents and $\mathrm{pH}$, and the subsequent risk of stone formation. ${ }^{17}$ The groups of dietary habits are classified as in Annex III. The dietary habits of thirty patients are given in table 1 . 
A diet rich in animal protein is associated with high uric acid urinary excretion and a low urinary $\mathrm{pH}$. Uric acid solubility decreases dramatically at a urinary $\mathrm{pH}$ lower that 5.5, leading to uric acid crystal formation. ${ }^{13}$ Populations that consume diets rich in animal protein (meat, fish and poultry) have a higher risk of stones than those with a more vegetarian diet. The risk of forming a stone is increased further by a high intake of refined sugar, salt (sodium chloride), oxalate-rich foods like spinach, tomatoes, soya beans and soya products, sesame seeds, nuts, peanut, chocolate, and tea without milk. ${ }^{14}$ In this study also the results have shown that higher consumption of alcohol, cigarettes, soya bean, spinach, sugar, salt, tomatoes, animal proteins, nuts, vitamin $\mathrm{C} / \mathrm{D}$ and calcium supplements can increase the risk of stone formation.

Table 1: Dietary Habits of Patients

\begin{tabular}{|c|l|c|c|c|}
\hline S.No. & Foods and Habits & No & Mild & Heavy \\
\hline 1 & Alcohol & 11 & 8 & 11 \\
\hline 2 & Smoking & 16 & 5 & 9 \\
\hline 3 & Soyabean & 1 & 14 & 15 \\
\hline 4 & Spinach & 0 & 17 & 13 \\
\hline 5 & Sugar & 1 & 14 & 15 \\
\hline 6 & Salt & 0 & 14 & 16 \\
\hline 7 & Tomatoes & 0 & 16 & 14 \\
\hline 8 & Animal proteins & 2 & 12 & 16 \\
\hline 9 & Nuts & 0 & 19 & 11 \\
\hline 10 & Vitamin C & 0 & 16 & 14 \\
\hline 11 & Calcium + Vitamin D & 8 & 12 & 10 \\
\hline
\end{tabular}

Common symptoms presented by the patients

The common symptoms presented by the thirty patients are given in the Table 2. The commonest symptoms were intermittent flank pain (100\%), nausea and vomiting (90\%), pain in the back and side of kidney zone $(86.7 \%)$, pain in the lower abdomen $(76.7 \%)$, difficulty in urinating $(43.3 \%)$ and feeling of incomplete emptying of bladder $(40 \%)$ followed by other symptoms like pain in groin, bladder distension etc. The less common symptom was observed to be dysuria (3.3\%).

Table 2: Symptoms reported by the patients

\begin{tabular}{|c|l|c|c|}
\hline S. No. & Symptoms & $\begin{array}{c}\text { No.of } \\
\text { Patients }\end{array}$ & Percentage \\
\hline 1 & Intermittent flank pain & 30 & 100 \\
\hline 2 & Nausea and vomiting & 27 & 90 \\
\hline
\end{tabular}

\begin{tabular}{|c|c|c|c|}
\hline 3 & Bladder distention & 10 & 33.3 \\
\hline 4 & Blood in the urine & 5 & 16.7 \\
\hline 5 & $\begin{array}{l}\text { Pain in the back and } \\
\text { side of kidney zone }\end{array}$ & 26 & 86.7 \\
\hline 6 & $\begin{array}{l}\text { Pain in the lower } \\
\text { abdomen }\end{array}$ & 23 & 76.7 \\
\hline 7 & Urge to urinate & 21 & 70 \\
\hline 8 & $\begin{array}{l}\text { Burning Sensation } \\
\text { during urination }\end{array}$ & 9 & 30 \\
\hline 9 & Dysuria & 1 & 3.3 \\
\hline 10 & Pain in Groin & 11 & 36.7 \\
\hline 11 & $\begin{array}{l}\text { Feeling of incomplete } \\
\text { emptying }\end{array}$ & 12 & 40 \\
\hline 12 & Nocturia & 7 & 23.3 \\
\hline 13 & Slow stream of urine & 6 & 20 \\
\hline 14 & Difficulty in urinating & 13 & 43.3 \\
\hline 15 & Fever & 5 & 16.7 \\
\hline
\end{tabular}

\section{Results of Stone Expulsion}

In this study, the stone expulsion was observed in 23 out of 30 patients. The stone expulsion rate was found to be $76.66 \%$ $(23 / 30)$. The mean stone expulsion time in days was $7.69 \pm 2.89$, with the minimum days for expulsion as 4 and the maximum days for expulsion as 14 days. The expulsion rate for stone size less than $7.0 \mathrm{~mm}$ diameter is $36.72 \%$ with mean of expulsion days of $5.90 \pm 1.921$. The expulsion rate for stone size more than $7.0 \mathrm{~mm}$ diameter is $63.33 \%$ with mean of expulsion days of $9.33 \pm 2.708$ as shown in Table 3 .

Table 3: Stone size and the expulsion rate

\begin{tabular}{|c|c|c|c|c|}
\hline $\begin{array}{c}\text { Stone } \\
\text { size in } \\
\text { mm }\end{array}$ & Number & $\begin{array}{c}\text { Mean of } \\
\text { expulsion } \\
\text { days }\end{array}$ & $\begin{array}{c}\text { Std. } \\
\text { deviation }\end{array}$ & Percentage \\
\hline $\begin{array}{c}\text { less than } \\
7.0\end{array}$ & 11 & 5.90911 & 1.921 & $36.72 \%$ \\
\hline $\begin{array}{c}\text { more than } \\
7.0\end{array}$ & 12 & 9.333 & 2.708 & $63.33 \%$ \\
\hline
\end{tabular}

The expulsion of the stones having the size less than $7.0 \mathrm{~mm}$ within 1st week and 2nd week of MET was in the ratio of 2.6:1 whereas this ratio for the expulsion of stones having the size larger than $7.0 \mathrm{~mm}$ was in the ratio $1: 1$. This clearly shows that the smaller the stone size, faster will be the stone expulsion. 
The correlation between the stone size and the days of the stone expulsion can be explained by the Pearson Correlation value. This value was analyzed with the use of correlation bivariate test in SPSS 15.0 version for windows. The Pearson correlation value is 0.662 which indicates that the there is positive strong relationship between the stone size and the days for the stone expulsion. The stone expulsion time is strongly correlated with the size of ureteric stone. If the size of the stone is small then, it will take less time to pass through the distal ureter and pass through the urine during urination. Similarly, if the size of stone large then it will take more time to pass through the distal ureter and to pass through the urine.

The $\mathrm{p}$-value is $0.0005(\mathrm{p}<0.01)$, which indicates that the correlation between the size and expulsion days is statistically significant at the confident level of $99.0 \%$.

The overall expulsion rate for stones with size less than or equal to $10 \mathrm{~mm}$ was $76.66 \%$. The expulsion rate for stones having size less than $7.0 \mathrm{~mm}$ was $100 \%$ while the expulsion rate for stones having size more than $7.0 \mathrm{~mm}$ was $63.15 \%$ as in Figure 1. This concludes that the expulsion rate and the days of stone expulsion is dependent upon the size of stone.

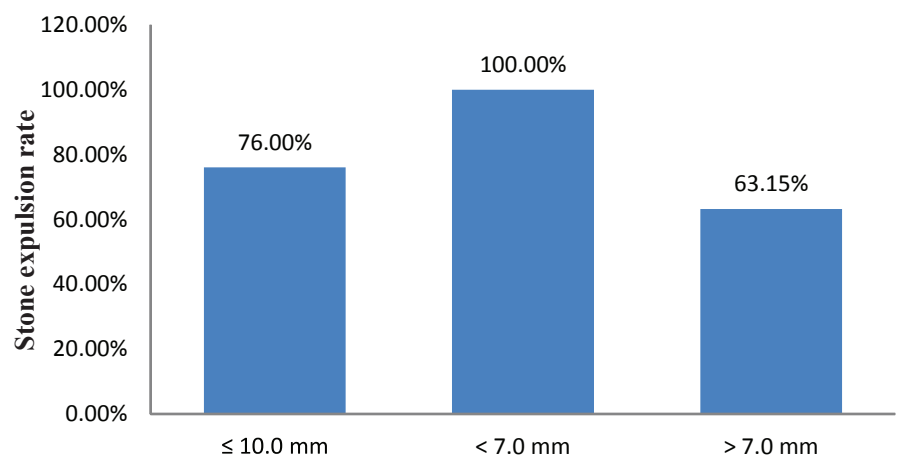

Figure 1: Stone expulsion rate in different stone size.

The total number of distal ureteric stones on the left ureter was found to be 12 out of which the stone expulsion rate was 91.66 $\%$. The total number of distal stones on the right ureter was found to be 18 and the stone expulsion was $66.66 \%$ as shown in Table 4.

Table 4: Stone side and Stone expulsion rate

\begin{tabular}{|c|c|c|c|}
\hline $\begin{array}{c}\text { Location } \\
\text { of Stone }\end{array}$ & Total number & $\begin{array}{c}\text { Success } \\
\text { number }\end{array}$ & $\begin{array}{c}\text { Stone expulsion } \\
\text { rate }\end{array}$ \\
\hline Left & 12 & 11 & $91.66 \%$ \\
\hline Right & 18 & 12 & $66.66 \%$ \\
\hline Total & 30 & 23 & \\
\hline
\end{tabular}

The highest rate of stone expulsion of $39.13 \%$ was observed in age groups of $18-28$ years, followed by $21.73 \%$ in $28-38$ years, $13.04 \%$ in $38-48,13.04 \%$ in $58-68$ years and $8.69 \%$ in $68-78$ years. The least success rate was seen in age groups of 48-58 years as shown in Figure 2.

This indicates that, the MET using Tamsulosin $0.4 \mathrm{mg}$ is effective both in younger age patients and in old aged patients.
The least success rate seen at the age 48-58 years may be due to obesity, decrease in metabolic functions and co morbid disease conditions like prostatomegaly and recurrent stone diseases.

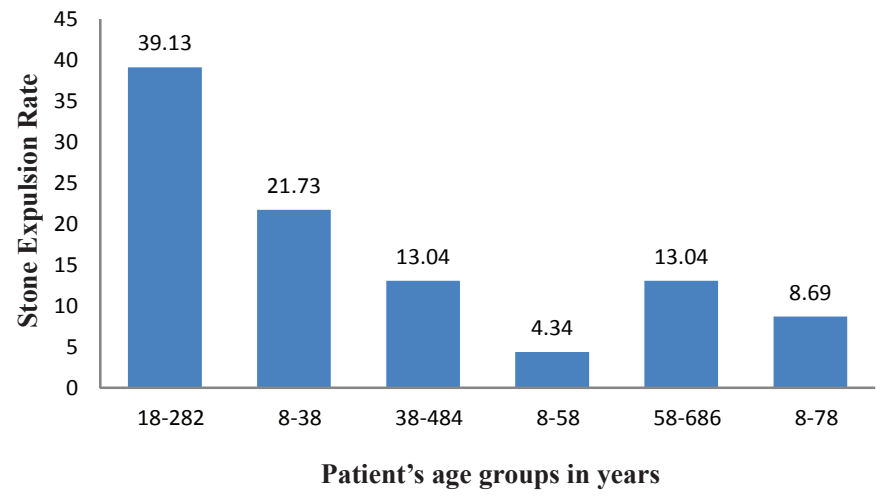

Figure 2: Stone expulsion rate in different age groups.

According to Holmlund's study, a stone in the ureter passes when the force that tends to move it down the ureter exceeds the friction between the stone and the ureteric wall. Ureteric relaxation in the region of the stone is considered to be an important factor promoting stone passage. The factors that affect the spontaneous passage of ureteric calculi are the size and shape of the stone, intrinsic areas of narrowing within the ureter, ureteric peristalsis, hydrostatic pressure of the column of urine proximal to the calculus and edema, inflammation, and spasm of the ureter at the site at which the stone is lodged. If the friction between the intraureteric wall and stone decreases then, ureteric relaxation occurs and promotes stone passage at the site of obstruction. Two factors that appear to be most useful in facilitating stone passage are an increase in hydrostatic pressure proximal to a calculus and relaxation of the ureter in the region of the stone. ${ }^{3}$ In the study done by Robinson $\mathrm{M}$. et.al., spontaneous passage of ureteric stones was seen in 27 patients $(77.1 \%)$ in the Tamsulosin group and the expulsion rate of ureteric stones greater than $4.0 \mathrm{~mm}$ diameter, was $50 \%{ }^{8}$ Stone size has been identified as an important predictive factor for ureteric stone expulsion. The probability for distal ureteric stones to pass sontaneously is as high as 71-98\% for stones less than $5 \mathrm{~mm} .{ }^{11}$ Tamsulosin has a fast onset of action and has been effective in patients with moderate or severe symptoms. Therefore, Tamsulosin is a useful therapeutic option in the management of patients with moderate to severe symptoms due to distal ureteric stone. ${ }^{18}$

\section{Economical benefits of MET}

Considering the patients conditions and their health status, the seven patients without the stone expulsion were suggested by the doctor for Utereroscopy ( 5 patients) and ESWL ( 2 patients). The maximum cost required for MET by using Tamsulosin 0.4 mg capsules is estimated as about Rs. 180. The cost for other procedures like ESWL and utereroscopy ranges from Rs. 20,000 to Rs. 25,000. Given the low cost of MET and the expense of stone procedures like ESWL (Rs 25,000) and Utereroscopy (Rs.20,000), these observevations are likely to have significant economic implications for the Nepalese health care system. The patient with stone size less than $10 \mathrm{~mm}$ will be beneficial with the effectiveness and low cost of Tamsulosin therapy for at least two weeks. This therapy not only economically beneficial the patients but also decrease the chances of complications due to 
the use of other interventions for stone removal.

\section{Improvement in symptoms}

The improvement in symptoms after the administration of Tamsulosin $0.4 \mathrm{mg}$ capsule was observed during the follow up study of all patients. There was marked improvement in the blood creatinine level; episodes of vomiting and colic pain; and the urine frequency. The symptoms like burning in micturation and difficulty in urination were also improved in all patients who had these symptoms before the treatmeant. All of these improvements in patients' symptoms were observed within the first week of MET.

The total number of patients with colic pain was found to be $11(36.66 \%)$. Out of them only 8 patients $(26.66 \%)$ consumed analgesic only once during 2 weeks of MET for the pain management.

Tamsulosin showed efficacy comparable to that of other management for removing the stone, thus offering excellent pain relief, with lower use of analgesics. ${ }^{19}$ Numerous studies have demonstrated that patients with ureteric stones treated with Tamsulosin have a statistically significant higher stone passage rate than those who do not receive Tamsulosin. Tamsulosin has also been shown to decrease the time for stone passage in patients with ureteric stones. Another benefit of Tamsulosin is that it decreases the episodes of renal colic and hence decrease the need for analgesics. ${ }^{20}$

Table 5: Improvement in symptoms after MET $(n=30)$

\begin{tabular}{|l|c|c|}
\hline Parameters & Before MET & After MET \\
\hline $\begin{array}{l}\text { Mean Creatine } \\
\text { concentration(mg/dl) }\end{array}$ & 0.957 & 0.78 \\
\hline Mean episodes of vomiting & 2.73 & 0.07 \\
\hline Mean episodes of colic pain & 3.03 & 0.37 \\
\hline Mean urine frequency & 7.48 & 5.87 \\
\hline Burning in micturation & Moderate & Improved \\
\hline Difficulty to urinate & Moderate & Improved \\
\hline
\end{tabular}

Common side effects observed

The common side effects after the administration were observed during the follow up of the patients. None of the side effects was observed in $56.7 \%$. The common presenting side effects were orthostatic hyptotension $(26.7 \%)$, headache $(13.3 \%)$, dizziness $(6.7 \%)$, sore throat $(6.7 \%)$ followed by fatigue $(3.3$ $\%$ ) and abnormal ejaculation (3.3\%). A 13-weeks' trial done in US showed that abnormal ejaculation, headache, dizziness, rhinitis, pharyngitis, infection, asthenia and diarrhea occurred in $>5 \%$ of patients treated daily with Tamsulosin $0.4 \mathrm{mg}$ or 0.8 $\mathrm{mg}$. It was well tolerated in long-term studies. The incidence of adverse events did not increase with continued exposure to Tamsulosin 0.4 or $0.8 \mathrm{mg} /$ day in the 40 -week, double-blind, extension study. ${ }^{18}$
Table 6: Common side effects of Tamsulosin

\begin{tabular}{|l|l|c|c|}
\hline S. No. & Side effects & Frequency & Percentage \\
\hline 1 & No symptoms & 17 & 56.7 \\
\hline 2 & Headache & 4 & 13.3 \\
\hline 3 & Dizziness & 2 & 6.7 \\
\hline 4 & Diarrhea & 0 & 0 \\
\hline 5 & Abnormal ejaculation & 1 & 3.3 \\
\hline 6 & Orthostatic hypotension & 8 & 26.7 \\
\hline 7 & Nausea and vomiting & 0 & 0 \\
\hline 8 & Rhinitis & 0 & 0 \\
\hline 9 & Fatigue & 0 & 0 \\
\hline 10 & Sore throat & 2 & 3.3 \\
\hline 11 & Insomnia & 0 & 0 \\
\hline 12 & Blurred vision & & \\
\hline 13 & Running or stuffy nose & 0 & \\
\hline
\end{tabular}

\section{CONCLUSION}

The study on effectiveness of Tamsulosin for medical management of Distal ureteric stone was successful conducted in Bir Hospital, Kathmandu with expulsion rate of $76.66 \%$ (23 out of 30 patients).

Tamsulosin, the most studied adrenoceptor antagonist for medical expulsion therapy of distal ureteric stones, reduces analgesic need, increases the chance of spontaneously passing the stone and decreases the episodes of colic pain. The expulsion rate of distal ureteric stones having size $\leq 10.0 \mathrm{~mm}$ was found to be $76.66 \%$, with only $26.66 \%$ of analgesic consumption, with decrease in colic episodes by $36.66 \%$ and lesser evidence of side effects. The most common side effects observed in 30 patients were orthostatic hypotension $(26.7 \%)$, headache $(13.3$ $\%)$, dizziness $(6.7 \%)$, sore throat $(6.7 \%)$ followed by fatigue (3.3\%), abnormal ejaculation (3.3\%) and no any side effects were observed on $56.7 \%$. The preventive measurement includes daily intake of a suitable liquid volume (minimum $2 \mathrm{~L}$ water/ day), a strict vegetarian diet, and excessive animal protein diets must be avoided. The use of Tamsulosin for Medical Expulsive Therapy is of high efficacy with minimum side effects, can be the excellent and beneficial patient satisfaction economically and socially.

\section{ACKNOWLEDGEMENT}

We are thankful to patients who participated in this study and Bir Hospital, Kathmandu,Nepal where the study was conducted. We are also grateful to Department of Pharmacy, 
Kathmandu University for the approval of this study as well as Ohm Pharmaceuticals Ltd. for the help during this study.

\section{REFERENCES}

1. Yencilek F, Erturhan S, Onder C, Koyuncu H, Erol B, Sarica K. Does Tamsulosin Change the Management of proximally located Ureteric Stones? Urological Research 2010;38:195-199.

2. Francesco P, Gianpalo G, Cristian F, Dario F, Roberto MS. Nifedipine versus Tamsulosin for the Management of Lower Ureteric Stones. The journal of urology 2004;172:568571.

3. Resim S, Ciftci A. Effect of Tamsulosin on the number and intensity of ureteric colic in patients with lower ureteric calculus. International Journal of Urology 2005;12:615-620.

4. Agrawal M, Gupta M, Gupta A, Agrawal A, Sarkari A, Lavania P. Prospective Randomized Trial Comparing Efficacy of Alfuzosin and Tamsulosin in Management of Lower Ureteric Stones. Ambulatory \& Office Urology, Journal of Urology 2009;73: 706-709.

5. Micali S, Grande M, Sighinolfi MC, Carne C, Stefani S, Bianchi G. Reviews in Endourology: Medical Therapy of Urolithiasis. Journal of Endourology 2006;20: 841-847.

6. Singh A, Alter HJ, Littlepage A. A Systematic Review of Medical Therapy to Facilitate Passage of Ureteric Calculi. Annals of Emergency Medicine 2007;50: 552-563.

7. Borghi L, Meschi T, Amato F, et al. Nifedipine and methylprednisolone in facilitating ureteric stone passage: a randomized, double-blind, placebo-controlled study. J Urol. 1994; 152:1095-1098.

8. Robinson MF, Jessica NW, Tania DS, Andrew DP. Tamsulosin for Ureteric Stones in the Emergency Department: A Randomized, Controlled Trial. Annals of Emergency Medicine 2009;54: 432-439.

9. Williamson KAL, Jarvis B, Wagstaff AJ. Tamsulosin An Update of its Role in the Management of Lower Urinary Tract Symptoms. Drugs 2002;62 (1):135-167.

10. Mukhia R, Shrestha K, Dahal P, Sharma VK. Study on chemical composition of urinary stones and its association with urinary tract infection 2001;1-5.

11. Thomas H, Peter S, Kaspar R, Thomas F, Tullio S, Rato TS.
Is There a Role for Tamsulosin in the Treatment of Distal Ureteric Stones of $7 \mathrm{~mm}$ or Less? Results of a Randomised, Double-Blind, Placebo-Controlled Trial. European Urology 2009;56: 407-412.

12. Yilmaz E, Batislam E, Basar MM, Tulgu MF, Basar H. The comparison and efficacy of 3 different 1-adernergic blockers for distal ureteric stones. The Journal of Urology 2005;173:2010-2012.

13. Scales CD, Curtis LH, Norris RD, Springhart WP, Sur RL, Schulman KA, Preminger GM. Urolithiasis/Endourology, Changing Gender Prevalence of Stone Disease. The Journal of Urology 2007;177: 979-982.

14. Ajayi L, Jaeger P, Robertson W. Obstruction and Infection: Renal Stone Disease Medicine 2007;35:415-419.

15. Kumar A, Singh S, Singh D. Evaluation of Urinary Abnormalities In Urolithiasis Patients From "Kathmandu Region". Journal of Clinical and Diagnostic Research 2008;3:847-853.

16. Semins MJ, Matlaga BR. Medical evaluation and management of urolithiasis. Therapeutic Advances in Urology 2010;2:1-9.

17. Bailly GG, Norman RW, Thompson C. Effects of Dietary Fat on the Urinary Risk Factors of calcium stone disease. Urology 2000;56: 40-44.

18. Williamson KAL, Wagstaff AJ. An Update of its Role in the Management of Lower Urinary Tract Symptoms. Drugs 2002;62:135-167.

19. Sio MD, Autorino R, Lorenzo GD, Damiano R, Giordano D, Cosentino L, Pane U, Giacomo FD, Mordente S, Armiento MD. Medical Expulsive Treatment of DistalUreteric Stones Using Tamsulosin: A Single-Center Experience. Journal of Endourology 2006;20:12-16.

20. Lipkin M, Shah O. Medical Therapy of Stone Disease: From Prevention to Promotion of Passage Options. Current Urology Reports 2009;10:29-34. 